\title{
Smart Tourism Recommendation Model: A Systematic Literature Review
}

\author{
Choirul Huda, Arief Ramadhan*, Agung Trisetyarso, Edi Abdurachman, Yaya Heryadi \\ Computer Science Department, BINUS Graduate Program - Doctor of Computer Science \\ Bina Nusantara University, Jakarta, Indonesia
}

\begin{abstract}
The tourism industry has become a potential sector to leverage economic growth. Many attractions are detected on several platforms. Machine learning and data mining are some potential technologies to improve the service of tourism by providing recommendations for a specific attraction for tourists according to their location and profile. This research applied for a systematic literature review on tourism, digital tourism, smart tourism, and recommender system in tourism. This research aims to evaluate the most relevant and accurate techniques in tourism that focused on recommendations or similar efforts. Several research questions were defined and translated into search strings. The result of this research was promoting 41 research that discussed tourism, digital tourism, smart tourism, and recommender systems. All of the literature was reviewed on some aspects, in example the problem addressed, methodology used, data used, strength, and the limitation that can be an opportunity for improvement in future research. This study proposed some references for further study based on reviewed papers regarding tourism management, tourist experience, tourist motivation, and tourist recommendation system. The opportunities for a further research study can be conducted with more data usage especially for a smart recommender system in tourism through many types of recommendation techniques such as content-based, collaborative filtering, demographic, knowledge-based, community-based, and hybrid recommender systems.
\end{abstract}

Keywords-Systematic review; tourism; smart tourism; digital tourism; recommender system

\section{INTRODUCTION}

The tourism industry sector has become a potential sector for economic growth in various regions. The World Tourism Organization (UNWTO) reported in January 2020 that the international tourism arrival reached 1.5 billion with a growing percentage of 4\% in 2019 [1]. This growth will certainly take place in line with the discovery of various new tourist destinations in various regions. In China, the tourism market growth of inbound and outbound tourism changed markedly in the past few years [2]. This potential tourism industry growth was also found in Thailand [3].

Tourism industries have faced a hard challenge since the coronavirus disease 2019 (COVID-19) pandemic. This pandemic has hurt the global economy, causing unprecedented global health and social emergencies [4]. Some studies have stated that this pandemic will end in the next few years so that it can help the growth of the tourism sector as in the previous year. Every country has a different level of rebound from the COVID-19 pandemic according to the numbers of daily

\footnotetext{
*Corresponding Author.
}

confirmed COVID-19 cases [4]. Tourism managers should establish marketing strategies and improve their service [5].

As the tourism industry gets an opportunity to rebound, it is necessary to prepare adequate strategies and activities to be able to provide good service for every tourist and all stakeholders. This preparation needs to involve all stakeholders by paying attention to their respective roles. Intrinsic motivation and extrinsic motivation had a highly positive impact on perceived trust in the tourism industry [6]. The aim of this study is to conduct a literature review that supports the preparation of a tourism recommendation model that focuses on two aspects, namely tourist attractions, and tourist smart services. Along with the development of information technology, today we are faced with the flow of information that floods various media regarding searching for some tourism information. Information on various attractions in various locations can be obtained through various media. Some of the media or sources of information that we conventionally use to find information related to tourism include travel agents, brochures, and social media [7].

Human lifestyle in the tourism and hospitality areas has been influenced by Information and Communication Technologies (ICT) [8]. Today, ICT has become a strategic platform for business and other purposes. Digital technologies as a part of ICT have introduced important innovations in many human aspects of life such as factories, hospitals, hotels, cities, and territories [9]. By using a mobile device, as a popular digital technology, many people can get information easily. They can brow some web site, search engines, social media, and any other digital platform to get the needed information. In some cases, they get private messages or notifications for some uninteresting information. The flooding of information sometimes harms some people because of unsuitable information. For getting tourism information people can use some search engine manually. Of course, this searching is not efficient yet because they will get the flooding of information even though they have used keywords for searching. Frequently mobile devices have been used by contemporary travelers for making decisions in traveling and managing travel itineraries [8]. Furthermore, travel, tourism, and hospitality companies have started to adopt some digital technologies such as Artificial Intelligence (AI), robots, and service automation (RAISA) through chatbots, delivery robots, the concierge of a robot, conveyor restaurants, self-service kiosks, and many others [9].

Regarding the trend of smart ICT especially in intelligent systems and location detection, the tourism industry has the 
opportunity to improve better services for stakeholders. Through smart ICT Tourist as a user of tourism industry needs more smart system and dynamics recommendation for specific recommendation in tourism in order to improve tourism experience and tourism service. Smart tourism is various changes driven by the application of some new technologies in tourism and it is a modernization of providing tourism service, innovating tourism management, improving tourism experience, and optimizing the tourism resources usage [10]. It would be important for managers of destinations to make greater development in the tourism destination resources, in order to provide a competitive advantage and enhance experiences [11]. Interactive solution through online media is needed for potential tourist for improvement of their tourism experience [12]. The smart technology solution in tourism should consider some effectiveness and healthy of tourism experience related to digital well-being experienced [13]. Search strings as the form of research questions translation were used in this Systematic Literature Review (SLR) method regarding the need for appropriate search results.

\section{METHOD}

For achieving the objective, this SLR has three main phases: Planning the Review, Conducting the Review, Reporting the Review [14]. Additional explanation of these main phases and the sub-phases is showed in Fig. 1.

All the stages listed in Fig. 1 may appear to be sequential, but practically some of the stages can be repeated for further review. This review is conducted to summarize the existing literature related to the relevant and accurate techniques for recommender systems in tourism through the defined problem, method, data usage, strength, and limitation.

This review protocol is built to reduce bias from the researcher in the selection of individual studies that may be influenced by researcher intentions [14]. The SLR activities also adopt several approaches in [15]. The review protocol is shown in Fig. 2. The steps of the review protocol are slightly modified to achieve the aim of this research.

There are ten steps of the review protocol according to Fig. 2. The activities are arranged in sequence as a guideline before the review of papers conducted. The first step of the review protocol is defining or formulating the research question (RQ) as the most important activity during protocol [14]. The research questions are showed in Fig. 3.

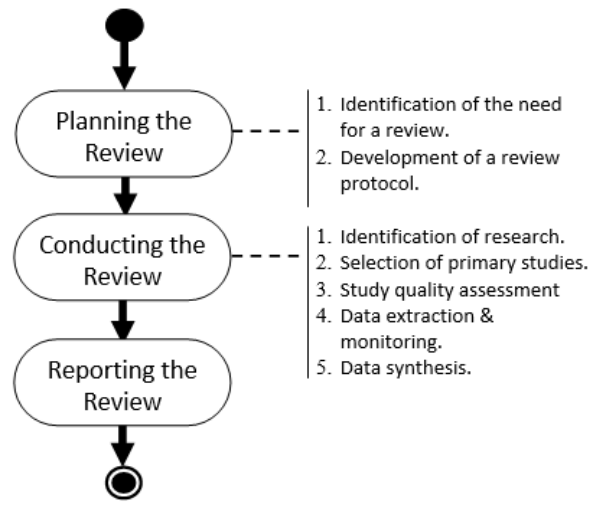

Fig. 1. The Phases of SLR.

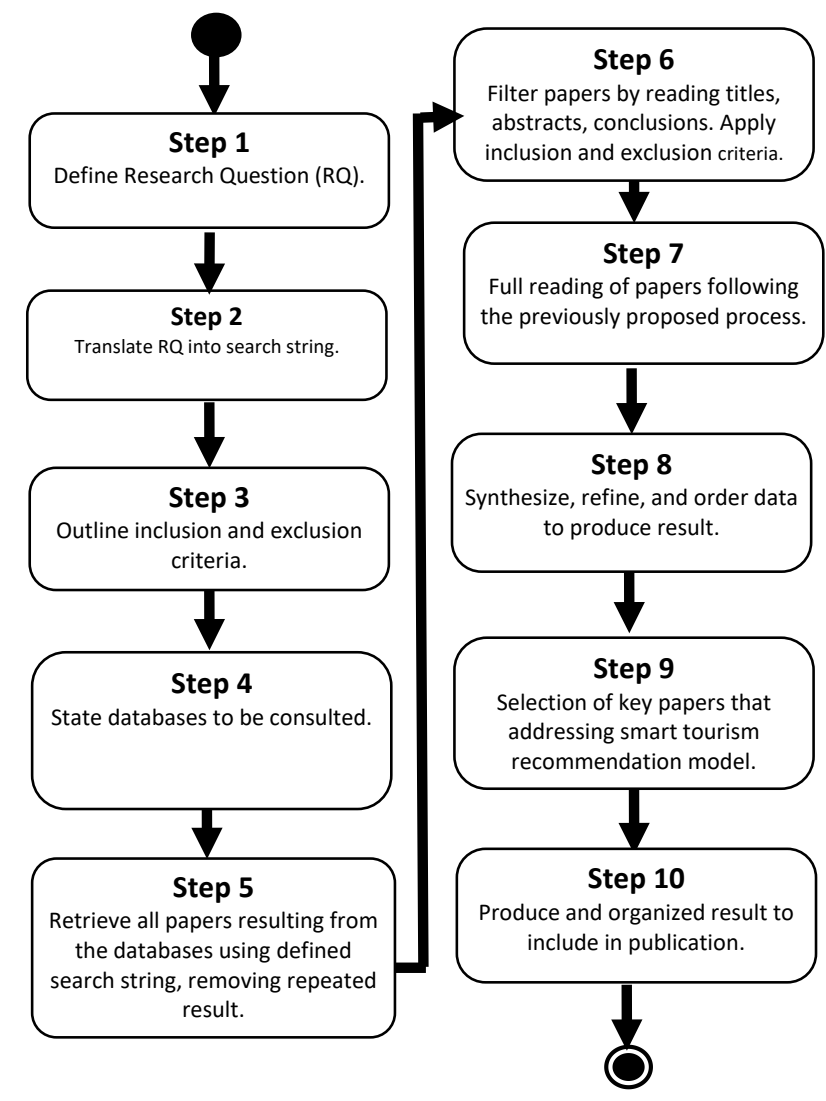

Fig. 2. Steps of the Review Protocol.

RQ1

RQ2

RQ3
What is the problem to be solved?

What kind of data is being used?

What kind of methodology is being used?

Fig. 3. Defined Research Questions.

The second step is translating the RQ into search strings such as: "Tourism”, "Digital Tourism”, "Smart Tourism”, "Recommender System". The complete search strings can be seen in Fig. 4. The third step is to outline the inclusion and exclusion criteria to specifying the selected paper according to the inclusion aspect and exclusion aspect. The inclusion is intuition aspect that is considered for further process, while the exclusion is the aspect that should be consideration of rejection. The further explanation of the inclusion aspects, exclusion aspects, and justifications are showed in Table I.

\begin{tabular}{|c|l|}
\hline String1 & "Tourism" \\
\hline String2 & "Digital Tourism" \\
\hline String3 & "Smart Tourism" \\
\hline String4 & ("Recommender System" AND “Tourism") \\
\hline String5 & ("Recommendation System" AND “Tourism") \\
\hline
\end{tabular}

Fig. 4. Search Strings. 
TABLE I. CRITERIA (INCLUSION, EXCLUSION), AND RELATED JUSTIFICATION

\begin{tabular}{|l|l|}
\hline Inclusion criteria & Justification \\
\hline $\begin{array}{l}\text { Published papers in } 2016 \text { to } 2021 \text { in } \\
\text { journal or conference proceedings. }\end{array}$ & Use the most recent findings only. \\
\hline $\begin{array}{l}\text { Papers present tourism study regarding } \\
\text { smart tourism recommendation model. }\end{array}$ & $\begin{array}{l}\text { The opportunity of smart tourism } \\
\text { recommendation model } \\
\text { development in the future. }\end{array}$ \\
\hline Exclusion criteria & Justification \\
\hline Not in English written papers. & $\begin{array}{l}\text { Standardization of international } \\
\text { language in English. }\end{array}$ \\
\hline $\begin{array}{l}\text { Paper is a secondary (review) or } \\
\text { tertiary study. }\end{array}$ & Focus on primary studies. \\
\hline
\end{tabular}

The fourth step is stating the reputable databases to be consulted for the source of papers. Several databases were classified into four groups according to authors' experiences and authors' decisions. The first group consists of IEEE, Elsevier, Science Direct, Springer, ProQuest, Emerald, Wiley, and UNWTO. The second groups consist of Routledge, IOP, MDPI, ICCT, and IJTC. The third group consists of ACIS, AITM, E3S, ICEB, and SAGE. The fourth group consists of CBUNI and Pertanika.

The review process was started by the first group and followed by the second group, third group, and finally fourth group. The searching process was conducted through the "Publish or Perish" application developed by Prof. Anne-Will Harzing [16], and Mendeley software applications. The fifth step is the retrieval of all papers resulting from the searching process and also removing repeated results. The sixth step is filtering papers by reading part of papers starting by reading the titles, abstracts, conclusions and then applying the inclusion and exclusion criteria. The seventh step is conducted by a full reading of papers following the reviewing part of papers, i.e. introduction, methodology, result and discussion, and any other part of papers. This step is conducted manually by reading every statement from all parts of the paper to find more implicit and explicit ideas and the relationship between every section in existing research. The eighth step is to synthesize, refine, and order extracted data to produce the result in some figures and tables. The result of this study is presented based on some aspects, and be analyzed based on the process, the database used, topics, and years of publication or conference. The ninth step is the selection of key papers that addressing the smart tourism recommendation model. The tenth step is producing and organizing the review result to be submitted in international publication.

\section{RESULTS}

The results in some topics seemed on a small number because of the specific requirement on searching proses and the result of the review protocol. Some papers were retrieved but many of them were not providing the recommender system in tourism through computer science research.

Steps of filtering papers were conducted through searching from the databases according to the defined search strings. The summary of this process is presented in Table II. Because of similarity in content, the result from searching by using ("Recommender System" AND "Tourism") and ("Recommendation System” AND “Tourism”) as search strings are summarized become one-row label: "Recommender System" at Table II.

Summary of publication period and related databases used on searching based on steps above are presented in Table III.

The locations of selected research were distributed into many regions or continentals with the majority of research were established in Asia (China, Indonesia, Japan, India, and Hong Kong). Further information on distributed research by region is displayed in Table IV. This discussion consists of some topics according to the topics in the searching process. The discussion was sequentially be arranged through Tourism, Digital Tourism, Smart Tourism, and Recommender Systems. The questions of what, why, how, when, where, and who were considered on every discussion based on the available information on each paper.

TABLE II. SEARCH RESULT

\begin{tabular}{|l|l|l|l|l|}
\hline TOPIC & $\begin{array}{l}\text { REVIE } \\
\text { W }\end{array}$ & $\begin{array}{l}\text { DEEP } \\
\text { REVIEW }\end{array}$ & $\begin{array}{l}\text { RELEVA } \\
\text { NT }\end{array}$ & $\begin{array}{l}\text { SELECT } \\
\text { ED }\end{array}$ \\
\hline Tourism & 36 & 17 & 15 & 13 \\
\hline Digital Tourism & 15 & 11 & 11 & 10 \\
\hline Smart Tourism & 25 & 15 & 13 & 13 \\
\hline $\begin{array}{l}\text { Recommender } \\
\text { System }\end{array}$ & 6 & 6 & 6 & 5 \\
\hline Total & $\mathbf{8 2}$ & $\mathbf{4 9}$ & $\mathbf{4 5}$ & $\mathbf{4 1}$ \\
\hline
\end{tabular}

TABLE III. SELECTED PAPERS BY DATABASE USED AND YeAR OF PUBLICATIONS

\begin{tabular}{|l|l|l|l|l|l|l|l|}
\hline \multirow{2}{*}{ DATABASE } & \multicolumn{2}{|l}{ YEARS } & \multirow{2}{*}{ TOTAL } \\
\cline { 2 - 7 } & $\mathbf{2 0 2 1}$ & $\mathbf{2 0 2 0}$ & $\mathbf{2 0 1 9}$ & $\mathbf{2 0 1 8}$ & $\mathbf{2 0 1 7}$ & $\mathbf{2 0 1 6}$ & \\
\hline Elsevier & 3 & 1 & 0 & 0 & 0 & 1 & $\mathbf{5}$ \\
\hline IEEE & 1 & 2 & 1 & 2 & 1 & 0 & $\mathbf{7}$ \\
\hline IOP & 1 & 2 & 1 & 1 & 0 & 0 & $\mathbf{5}$ \\
\hline MDPI & 0 & 5 & 0 & 0 & 0 & 0 & $\mathbf{5}$ \\
\hline ProQuest & 0 & 1 & 0 & 0 & 0 & 0 & $\mathbf{1}$ \\
\hline Routledge & 0 & 3 & 4 & 0 & 0 & 0 & $\mathbf{7}$ \\
\hline SAGE & 0 & 2 & 1 & 0 & 0 & 0 & $\mathbf{3}$ \\
\hline Science Direct & 0 & 2 & 2 & 0 & 1 & 0 & $\mathbf{5}$ \\
\hline Springer & 1 & 0 & 1 & 0 & 0 & 0 & $\mathbf{2}$ \\
\hline UNWTO & 0 & 1 & 0 & 0 & 0 & 0 & $\mathbf{1}$ \\
\hline TOTAL & $\mathbf{6}$ & $\mathbf{1 9}$ & $\mathbf{1 0}$ & $\mathbf{3}$ & $\mathbf{2}$ & $\mathbf{1}$ & $\mathbf{4 1}$ \\
\hline
\end{tabular}

TABLE IV. Selected PAPERs by Database Used AND Regions

\begin{tabular}{|c|c|c|c|c|c|}
\hline \multirow[b]{2}{*}{ REGIONS } & \multicolumn{4}{|l|}{ TOPICS } & \multirow{2}{*}{$\begin{array}{l}\text { TOTA } \\
\text { L }\end{array}$} \\
\hline & $\begin{array}{l}\text { Digital } \\
\text { Tourism }\end{array}$ & $\begin{array}{l}\text { Recommend } \\
\text { er System }\end{array}$ & $\begin{array}{l}\text { Smart } \\
\text { Tourism }\end{array}$ & $\begin{array}{l}\text { Touris } \\
\text { m }\end{array}$ & \\
\hline Africa & 0 & 0 & 1 & 0 & 1 \\
\hline Asia & 3 & 2 & 9 & 6 & 20 \\
\hline Europe & 4 & 0 & 1 & 3 & 8 \\
\hline $\begin{array}{l}\text { South } \\
\text { America }\end{array}$ & 1 & 1 & 0 & 1 & 3 \\
\hline Global & 2 & 2 & 2 & 3 & 9 \\
\hline TOTAL & 10 & 5 & 13 & 13 & 41 \\
\hline
\end{tabular}




\section{Discussion}

\section{A. Tourism}

Thirteen papers were selected for this topic discussion below and introduction above. The authors in [1] and [4] provide the contribution, opportunity, and challenge of the tourism industry. How is the pandemic will rebound was stated in [4]. The first paper being analyzed is the paper produced by The World Tourism Organization (UNWTO) for the global tourism industry based on January 2020 report. Tourism industries face a hard challenge on Pandemic COVID-19, but it will be rebound for the next period according to research from [4] with various recovery levels for each country.

This sub-topic was discussed in [17] and [18]. The author in [17] used Exploratory Factor Analysis (EFA), T-test, and ANOVA analysis to explore tourists' motivations in China, and involvement in adventure tourism activities, and also the kinds of personality and location affect their motivation and involvement in 2019. This research provided the reasons for preferred adventure activities and key requirements of adventure activity but using a relatively small sample size and only focus on adventure tourism in Chengdu and Xiamen, China.

Lindberg et. al. in [18] describe the integrated analysis of individual characteristics, such as attitudes and demographic factors, and situational characteristics, such as interpretive center features through discrete choice models use random utility theory in Norway in 2019. This paper gave an excellent aspect of analysis based on respondent characteristics according to basic demographic data (gender, education, age, and income) but has limitations on the generalization of the demographic factor for other locations like Asia. The author in [19] explains tourist experience regarding the judgment of tourists' willingness to pay to increase the public managers' income to produce policies through binary logistic regression and decision. This paper used travel characteristics and variables of sociodemographic of tourists visiting Andalusia (Spain) in 2021.

Based on the research question and discussion in tourism, the selected papers have some various problems to be solved. All of them can be seen in Table $\mathrm{V}$.

Based on the research question and discussion in tourism, the selected papers have some various data used, and methodologies used. All of them can be seen in Table VI.

Based on the research question and discussion in tourism, the selected papers have some various methodologies used. All of them can be seen in Table VII.

TABLE V. PROBLEM TYPES IN TOURISM TOPICS

\begin{tabular}{|l|l|l|}
\hline Problem & $\sum$ Papers & Selected Papers \\
\hline Tourism Management & 3 & [1], [2], [4] \\
\hline Tourist Experience & 4 & [12], [13], [19], [20] \\
\hline Tourist Motivation & 6 & [17], [18], [11], [3], [6], [5] \\
\hline TOTAL & $\mathbf{1 3}$ & \\
\hline
\end{tabular}

TABLE VI. DATA USED IN TOURISM TOPICS

\begin{tabular}{|l|l|l|}
\hline Data Used & $\sum$ Papers & Selected Papers \\
\hline Questionnaire & 7 & [17], [18], [19], [11], [12], [6], [5] \\
\hline Paper/ Report & 6 & [1], [4], [2], [3], [13], [20] \\
\hline TOTAL & $\mathbf{1 3}$ & \\
\hline
\end{tabular}

TABLE VII. METHOD TYPES IN TOURISM TOPICS

\begin{tabular}{|l|l|l|}
\hline Methods & $\sum$ Papers & Selected Papers \\
\hline Review & 4 & [1], [18], [13], [20] \\
\hline $\begin{array}{l}\text { Exploratory factor analysis } \\
\text { (EFA), T-test, and ANOVA }\end{array}$ & 1 & {$[17]$} \\
\hline $\begin{array}{l}\text { Exploratory Factor Analysis } \\
\text { through Kaiser-Meyer-Olkin } \\
\text { (KMO) }\end{array}$ & 1 & {$[3]$} \\
\hline $\begin{array}{l}\text { Exploratory Factor Analysis } \\
\text { through K-means, ANOVA }\end{array}$ & 1 & {$[5]$} \\
\hline Statistical Model & 6 & [4], [19], [11], [2], [12], [6] \\
\hline TOTAL & 7 & \\
\hline
\end{tabular}

\section{B. Digital Tourism}

The next topic discussion is digital tourism that is a fundamental platform for smart tourism recommendation models through digital technology. Digital tourism is a part of digital transformation in the tourism industry that used digital technology as a strategic platform for transformation from the traditional approach to digital. The digital platform offers a better solution for tourism rather than the traditional approach through a more effective and efficient service for stakeholders in tourism. Some various approach was conducted at the existing research in different regions. Ten papers were selected at final review: [8], [9], [10], [21], [22], [23], [24], [25], [26], [27].

In [8], it was addressed the problem of overuse in technology-related addiction issues and mental health regarding tourism context has been explored through literature review and exploratory study about the perception of 17 participants on 2020. On the other hand, the impact of the digital revolution on tourism, the different and common work between tourism 4.0 and smart tourism through a conceptual approach is addressed in [9].

The author in [10] used blockchain technology to develop a tourism information intelligent service platform for tourism enterprises, tourists, government and promoted tourism management and service coordination, and economic development in China. In [21], it was developed a system to automatically recommend tourists to visit a particular tourist destination through an ontological approach. This approach included current situation detection such as location, existing fixed schedule, time, means of transportation, place accessibility to visit Japan in 2019.

Veloso et. al. in [22] identified the main challenges within tourism crowdsourcing platforms through a comparison of existing models. They detect future research trends to ensure the quality and authenticity of tourism-related crowdsourced data by using published papers about tourism crowdsourcing 
platforms. The author in [23] developed a software architecture that can be specified in a web application based on the proposal of a management model of the NTS-TS 002 standard through conceptual software design in Columbia. Paper [24] conducted IoT-based research on tourism industrial clusters and information platforms through niche principles and its theoretical framework in China.

Briciu in [25] use Virtual Reality and mobile application for city development in terms of cultural tourism solutions and evaluation on cultural heritage sites through descriptive analysis in Romania. The author in [26] conducted comparative and content analysis for tourism zone development in Russia's economic space through tourism technology platforms implementation. Paper [27] conducted a Blackwell-MiniardEngel model to develop a customer journey map creation in Russia.

Based on the research question and discussion in digital tourism, the selected papers have some various problems to be solved. All of them can be seen in Table VIII.

TABLE VIII. PRoBlem TyPeS In Digital TOURISM

\begin{tabular}{|l|l|l|}
\hline Problem & $\sum$ Papers & Selected Papers \\
\hline Tourism Management & 2 & [23], [24] \\
\hline Tourist Experience & 7 & [22], [21], [10], [9], [25], [26], [27] \\
\hline Tourist Motivation & 1 & [8] \\
\hline TOTAL & $\mathbf{1 0}$ & \\
\hline
\end{tabular}

Based on the research question and discussion in digital tourism, the selected papers have some various data used. All of them can be seen in Table IX.

TABLE IX. DATA USED IN DigITAL TOURISM

\begin{tabular}{|l|l|l|}
\hline Data Used & $\sum$ Papers & Selected Papers \\
\hline RDB & 1 & {$[10]$} \\
\hline Web Site & 3 & {$[10],[25],[26]$} \\
\hline Questionnaire & 1 & {$[8]$} \\
\hline Google Map & 1 & {$[10]$} \\
\hline Paper/ Report & 8 & {$[22],[21],[9],[23],[25],[24],[26],[27]$} \\
\hline TOTAL & $\mathbf{1 4}$ & \\
\hline
\end{tabular}

Based on the research question and discussion in digital tourism, the selected papers have some various methodologies used. All of them can be seen in Table X.

TABLE X. METHOD TYPES IN DigitAL TOURISM

\begin{tabular}{|l|l|l|}
\hline Methods & $\sum$ Papers & Selected Papers \\
\hline Review & 5 & [8], [22], [25], [26], [27] \\
\hline Conceptual Model & 5 & [21], [10], [9], [23], [24] \\
\hline TOTAL & $\mathbf{1 0}$ & \\
\hline
\end{tabular}

\section{Smart Tourism}

Further topic discussion is smart tourism that used various approaches in research and model development. Some papers used an intelligent approach while others used some different approaches. It was explored in [28], a tourist preference methodological approach of Smart Tourism Attractions (STA), and comprehensive review for the weaknesses and strengths of an STA through related study site, literature on Hongshan Zo in China, data collection by questionnaire for collecting the travel experience, and FCEM-AHP evaluation in 2016. The authors in [29] have addressed a definition comparison between traditional and smart tourism information services based on published papers.

Ramadhani in [30] explained the creation of the automatically rating system of tourism destination based on a travel blog through an automatic approach by a new semantic analysis algorithm in Indonesia in 2017. However, in [31], it was found the important factors for the tourists' preferences to visit the Vredeburg museum in Yogyakarta, Indonesia in 2018. This research provided the preferences of tourists towards smart tourism and having challenges for a more general purpose.

The author in [32] provides a better user travel experience of smart tourism in China in 2021. On the other hand, Dey in [33] focused on a literature study on Indian tourism sectors providing online services and talking about the current Artificial Intelligent used in India in 2020. It briefed technology usages in tourism and needs more introductions for implementation of recommender system in tourism.

A system is developed in [34] to arrange professional game rangers for a visitor in a particular tourist destination using machine learning through Google's TensorFlow based on animal mages in South Africa in 2018. The author in [35] introduced available datasets for the public in Europe regarding the area of tourism demand prediction for future comparisons and experiments using Pearson correlation analysis for features extracted from the environmental, social media, and official datasets.

Li in [36] extracted useful search query data and construct relevant econometric models. However, in [37] it was proposed the incorporation of reliable traditional methodologies with text analytics and machine learning to facilitate a deeper understanding of concepts and theory building through a stepby-step methodological and analytical framework based on an analysis of online reviews of existing research.

The author in [38] provided an understanding of the aspirations of people with visual impairments in terms of tourism and explore how smart tourism destinations could potentially enhance the tourism experience they offer. Qualitative research was adopted at this research through indepth expert interviews and multisensory observation and implemented the PERMA model as a framework for designing the app in Hong Kong. The author in [39] provides definitional clarity and a comprehensive approach to the smart tourism city anatomy regarding smart tourism and smart city through a conceptual approach. The author in [40] provided the relationship among smart tourism technology attributes, travel satisfaction, happiness, and revisit intention regarding travel experience satisfaction through the structural equation method in China. The questionnaire was conducted for Chinese tourists' travel satisfaction analysis. 
Based on the research question and discussion in smart tourism, the selected papers have some various problems to be solved. All of them can be seen in Table XI.

TABLE XI. PROBLEM TYPES IN SMART TOURISM

\begin{tabular}{|l|l|l|}
\hline Problem & $\sum$ Papers & Selected Papers \\
\hline Tourism Management & 2 & [39], [37] \\
\hline Tourist Experience & 9 & $\begin{array}{l}\text { [30], [34], [32] [33], [29] [35], } \\
\text { [36], [38], [40] }\end{array}$ \\
\hline Tourist Preference & 2 & {$[28],[31]$} \\
\hline TOTAL & $\mathbf{1 3}$ & \\
\hline
\end{tabular}

Based on the research question and discussion in smart tourism, the selected papers have some various data used. All of them can be seen in Table XII.

TABLE XII. DATA USED IN SMART TOURISM

\begin{tabular}{|l|l|l|}
\hline Data Used & $\sum$ Papers & Selected Papers \\
\hline RDB & 1 & {$[32]$} \\
\hline Web Site & 3 & {$[30],[34],[35]$} \\
\hline Social Media & 1 & {$[35]$} \\
\hline Questionnaire & 4 & {$[30],[31],[38],[40]$} \\
\hline Search Engine & 1 & {$[36]$} \\
\hline Paper/ Report & 5 & [28], [33], [29], [37], [39] \\
\hline TOTAL & $\mathbf{1 5}$ & \\
\hline
\end{tabular}

Based on the research question and discussion in smart tourism, the selected papers have some various methodologies used. All of them can be seen in Table XIII.

TABLE XIII. METHOD TYPES IN SMART TOURISM

\begin{tabular}{|l|l|l|}
\hline Methods & $\sum$ Papers & Selected Papers \\
\hline Review & 6 & [30], [28], [33], [29], [38], [39] \\
\hline Statistical Model & 3 & [31] [35], [40] \\
\hline Conceptual Model & 1 & [37] \\
\hline Intelligent Model & 3 & [34], [32], [36] \\
\hline TOTAL & $\mathbf{1 3}$ & \\
\hline
\end{tabular}

\section{Recommender Systems}

The final topic discussion is about Recommender Systems according to the selected papers: [7], [41], [42], [43], and [44]. In [7], it is offered a travel recommender system for the effects of automating Word-of-Mouth (WOM) and established personalized travel-planning services to tourists through Collaborative Filtering (CF)-based recommender using WOM communication. This research used tourists' preference ratings on some destinations through interpersonal communication in South Korea in 2019. The author in [41] provide a framework of a travel recommender system by combining knowledgebased filtering and hybrid recommendation methods with decision-making theory in China in 2020.

Sagar et al. in [42] developed a hotel recommender system based on collaborative filtering and regression. Whereas Roy and Dietz in [43] develop a travel recommender system based on the content-based recommender system method. This research used user information and preferences such as home region, destination region, traveler type, and maximum travel duration and fondness for different types of venues in a city through Twitter social media in 2021.

The author in [44] proposed a solution for detection of tourist implicit preferences based on photos from social media on Facebook, Instagram, and Google Plus, and recommend a set of emerging techniques for tourism such as Convolutional Neural Network (CNN) and fuzzy logic to classify tourists and provide the recommendation at Brazil on 2018. This research provided two recommendation types: item-based and userbased.

Based on the research question and discussion in recommender system in tourism, the selected papers have one type of problem to be solved. All of them can be seen in Table XIV.

TABLE XIV. PROBLEM TyPeS In RECOMMENDER SySTEM.

\begin{tabular}{|l|l|l|}
\hline Problem & $\sum$ Papers & Selected Papers \\
\hline Tourist Recommendation & 5 & [7], [44], [41], [43], [42] \\
\hline TOTAL & $\mathbf{5}$ & \\
\hline
\end{tabular}

Based on the research question and discussion in recommender system in tourism, the selected papers have various data used. All of them can be seen in Table XV.

TABLE XV. DATA USED IN RECOMMENDER SYSTEM

\begin{tabular}{|l|l|l|}
\hline Data Used & E Papers & Selected Papers \\
\hline RDB & 1 & {$[7]$} \\
\hline Web Site & 2 & {$[7],[42]$} \\
\hline Social Media & 2 & {$[44],[43]$} \\
\hline Paper/ Report & 1 & {$[41]$} \\
\hline TOTAL & $\mathbf{6}$ & \\
\hline
\end{tabular}

Based on the research question and discussion in recommender system in tourism, the selected papers have various methodologies used. All of them can be seen in Table XVI.

TABLE XVI. METHOD TYPES IN RECOMMENDER SYSTEM

\begin{tabular}{|l|l|l|}
\hline Methods & $\sum$ Papers & Selected Papers \\
\hline $\begin{array}{l}\text { Intelligent Model (AI, } \\
\text { ML, CNN, FL, CF) }\end{array}$ & 5 & [7], [44], [41], [43], [42] \\
\hline TOTAL & $\mathbf{5}$ & \\
\hline
\end{tabular}

This research found that motivation and preference in tourism should become a concern for a better tourist experience. Digital technology offers some efficiency and flexibility for the tourist experience. Implementation of digital tourism offers better integration for stakeholders for maintaining, searching, and decision making of tourism factors such as facility, attraction, location. Some approaches for digital tourism can be adopted from [10] and [9]. For further smart experience, a smart tourism solution should be conducted. Smart tourism development through any type of 
data format and intelligent models that will improve the tourist experience and management can be adopted from [34], [35], and [40]. A personal recommendation for a better tourist experience can be provided by a recommender system in tourism through various approaches. Recommender system improvement through Collaborative filtering and Contentbased Recommender systems can be adopted from [43], and [7] with further personalization and generalization for other attractions.

\section{IMPLICATION AND CONCLUSION}

This study provided 41 selected papers from various data sources, regions, and years that were reviewed and promoted as references for the next study on tourism, digital tourism, smart tourism, and recommender systems. This research found opportunities for further research in tourism based on the review and discussion of existing research through their addressed problems, methodologies, data usages, research times and locations, strengths, and limitations. The next study can be conducted on a different aspect of what, why, where, and how to solve the problem based on previous studies and the enhancement in the future. Due to the conceptual model provided from this research, some steps or development and result were provided on some figures that need further discussion.

The result of this study will help decision-makers in the tourism industry to improve their service for stakeholders in the tourism industry. Findings in tourism, digital tourism, smart tourism, and recommender system will help different approaches to decisions. Providing public policy in tourism and excellent facilities by local government will contribute to tourist experience and willingness to pay. The available personal recommendation will help the tourist to make a good decision in traveling. This study found some guidelines for tourism management to government through existing study. The opportunity of the tourism industry rebound after a pandemic should be prepared with adequate strategy although every country has a different scale of time to rebound.

Limitations of the current research regarding the scalability of data usage and quality of data usage and their methodologies can be enhanced to the next research. This study proposed some references for further study based on reviewed papers regarding tourism management, tourist experience, tourist motivation, and tourist recommendation system. The opportunities for a further research study can be conducted with more data usage especially for a smart recommender system in tourism through many types of recommendation techniques such as content-based, collaborative filtering, demographic, knowledge-based, community-based, and hybrid recommender systems. The tourist recommendation system in the future can be started with a study in link and match of personal demographics with available attractions on dynamic location through machine learning model, and location detection technology regarding available data in social media.

REFERENCES

[1] W. Tourism. and UNWTO, "UNWTO World Tourism Barometer and Statistical Annex, May 2020", UNWTO World Tourism Barometer, 18(2), 2020, pp. 1-48. doi: 10.18111/wtobarometereng.2020.18.1.2.
[2] H. Huang, '”The spatial distribution, influencing factors, and development path of inbound tourism in China-An empirical analysis of market segments based on travel motivation”, Sustainability (Switzerland), 12(6), 2020. doi: 10.3390/su12062508.

[3] P. Fakfare, "A scale development and validation on domestic tourists' motivation: the case of second-tier tourism destinations", Asia Pacific Journal of Tourism Research, 25(5), 2020, pp. 489-504. doi: 10.1080/10941665.2020.1745855.

[4] H. Zhanga, H. Song, L. Wen, and C. Liu, "Forecasting tourism recovery amid COVID-19”, Annals of Tourism Research, 87, 2021, p. 103149. doi: 10.1016/j.annals.2021.103149.

[5] M. Carvache-Franco, "Segmentation and motivations in eco-tourism: The case of a coastal national park", Ocean and Coastal Management, 178, 2019. doi: 10.1016/j.ocecoaman.2019.05.014.

[6] M. Kim, "The effects of motivation, deterrents, trust, and risk on tourism crowdfunding behavior”, Asia Pacific Journal of Tourism Research, 25(3), 2020, pp. 244-260. doi: 10.1080/10941665.2019.1687533.

[7] I. Choi, "A recommender system based on personal constraints for smart tourism city *”, Asia Pacific Journal of Tourism Research, 2019. doi: 10.1080/10941665.2019.1592765.

[8] I. Egger, "Digital free tourism - An exploratory study of tourist motivations", Tourism Management, 79, 2020. doi: 10.1016/j.tourman.2020.104098.

[9] T. Pencarelli, "The digital revolution in the travel and tourism industry", Information Technology and Tourism, 22(3), 2020, pp. 455-476. doi: 10.1007/s40558-019-00160-3.

[10] C. Wei, "Research on Construction of a Cloud Platform for Tourism Information Intelligent Service Based on Blockchain Technology", Wireless Communications and Mobile Computing, 2020. doi: 10.1155/2020/8877625.

[11] M. H. Pestana, "Motivations, emotions and satisfaction: The keys to a tourism destination choice", Journal of Destination Marketing and Management, 16, 2020. doi: 10.1016/j.jdmm.2018.12.006.

[12] D. Suhartanto, "Tourist loyalty in creative tourism: the role of experience quality, value, satisfaction, and motivation”, Current Issues in Tourism, 23(7), 2020, pp. 867-879. doi: 10.1080/13683500.2019.1568400.

[13] U. Stankov, "Digital well-being in the tourism domain: mapping new roles and responsibilities", Information Technology and Tourism, 2021. doi: 10.1007/s40558-021-00197-3.

[14] B. Kitchenham, "Procedures for performing systematic reviews", Keele, UK, Keele University, 2004.

[15] A. Ramadhan, D. I. Sensuse, Muladno, and A. M. Arymurthy, "Synthesizing success factors for e-government initiative", Research Journal of Applied Sciences, Engineering and Technology, Vo. 6, No. 9, 2013, pp. 1685-1702. doi: 10.19026/rjaset.6.3891.

[16] A. W. Harzing, "Publish or Perish", 2020, https://harzing.com/resources/publish-or-perish.

[17] X. Jin, "Motivation and involvement in adventure tourism activities: a Chinese tourists' perspective”, Asia Pacific Journal of Tourism Research, 24(11), 2019, pp. 1066-1078. doi: 10.1080/10941665.2019.1666152.

[18] K. Lindberg, K. Veisten, and A. H. Halse, "Analyzing the deeper motivations for nature-based tourism facility demand: a hybrid choice model of preferences for a reindeer visitor center”, Scandinavian Journal of Hospitality and Tourism, 19(2), 2019, pp. 157-174. doi: 10.1080/15022250.2018.1482565.

[19] J. L. Durán-Román, P. J. Cárdenas-García, and J. I. Pulido-Fernández, "Tourists' willingness to pay to improve sustainability and experience at destination”, Journal of Destination Marketing and Management, 19, 2021. doi: 10.1016/j.jdmm.2020.100540.

[20] J. Stienmetz, J. Kim, Z. Xiang, and D. R. Fesenmaier, "Managing the structure of tourism experiences: Foundations for tourism design", Journal of Destination Marketing and Management, 19, 2021. doi: 10.1016/j.jdmm.2019.100408.

[21] Z. Tang, and E. Pyshkin, "Ontological approach to personalized situational planning: Concept and scenarios”, Proceedings - 2019 IEEE International Conferences on Ubiquitous Computing and 
Communications and Data Science and Computational Intelligence and Smart Computing, Networking and Services, IUCC/DSCI/SmartCNS 2019, 2019, pp. 561-564. doi: 10.1109/IUCC/DSCI/SmartCNS.2019.00118.

[22] B. Veloso, F. Leal, B. Malheiro, and F. Moreira, "Distributed trust \& reputation models using blockchain technologies for tourism crowdsourcing platforms”, Procedia Computer Science, 160, 2019, pp. 457-460. doi: 10.1016/j.procs.2019.11.065.

[23] F. G. Ramirez, "Architecture of a Technology Platform for sustainable tourism management under the NTS-TS 002 standard”, IOP Conference Series: Materials Science and Engineering, 2019. doi: 10.1088/1757899X/519/1/012029.

[24] X. Li, "Research on tourism industrial cluster and information platform based on Internet of things technology", International Journal of Distributed Sensor Networks, 15(7), 2019. doi: 10.1177/1550147719858840.

[25] A. Briciu, "Evaluating how "smart" Brasov, Romania can be virtually via a mobile application for cultural tourism", Sustainability (Switzerland), 12(13), 2020. doi: 10.3390/su12135324.

[26] V. N. Sharafutdinov, "Tourism Technology Platforms as a Tool for Supporting Competitiveness of Regional Tourism Products”, Regional Research of Russia, 10(1), 2020, pp. 48-55. doi: 10.1134/S2079970520010104.

[27] T. Maslova, "Transformation of consumer behavior in the tourism industry in the conditions of digital economy”, IOP Conference Series: Materials Science and Engineering, 2020. doi: 10.1088/1757899X/940/1/012070.

[28] X. Wang, X. Li, F. Zhen, and J. H. Zhang, "How smart is your tourist attraction?: Measuring tourist preferences of smart tourism attractions via a FCEM-AHP and IPA approach”, Tourism Management, 54, 2016, pp. 309-320. doi: 10.1016/j.tourman.2015.12.003.

[29] Y. Li, C. Hu, C. Huang, and L. Duan, "The concept of smart tourism in the context of tourism information services”, Tourism Management, 58, 2017, pp. 293-300. doi: 10.1016/j.tourman.2016.03.014.

[30] D. Ramadhani, "Tourism destination rating system based on social media analysis (proposal and dataset development in Indonesian language)", Proceedings - 2017 International Conference on Sustainable Information Engineering and Technology, SIET 2017, 2018, pp. 41-46. doi: 10.1109/SIET.2017.8304106.

[31] R. Amanda, "Analysis of Tourists Preferences on Smart Tourism in Yogyakarta (Case: Vredeburg Fort Museum)”, Journal of Physics: Conference Series, 2018. doi: 10.1088/1742-6596/1007/1/012040.

[32] Y. Pei, and Y. Zhang, "A Study on the Integrated Development of Artificial Intelligence and Tourism from the Perspective of Smart Tourism”, Journal of Physics: Conference Series, 1852(3), 2021. doi: 10.1088/1742-6596/1852/3/032016.
[33] S. Dey, "Analytical study on use of AI techniques in tourism sector for smarter customer experience management”, 2020 International Conference on Computer Science, Engineering and Applications, ICCSEA 2020, 2020. doi: 10.1109/ICCSEA49143.2020.9132925.

[34] L. Butgereit, "On Safari with TensorFlow: Assisting Tourism in Rural Southern Africa Using Machine Learning”, 2018 International Conference on Advances in Big Data, Computing and Data Communication Systems, icABCD 2018, 2018. doi: 10.1109/ICABCD.2018.8465441.

[35] A. Khatibi, "FISETIO: A FIne-grained, Structured and Enriched Tourism Dataset for Indoor and Outdoor attractions', Data in Brief, 28, 2020. doi: 10.1016/j.dib.2019.104906.

[36] X. Li, "Machine Learning in Internet Search Query Selection for Tourism Forecasting”, Journal of Travel Research, 2020. doi: $10.1177 / 0047287520934871$.

[37] T. H. Le, "Proposing a systematic approach for integrating traditional research methods into machine learning in text analytics in tourism and hospitality”, Current Issues in Tourism, 2020. doi: 10.1080/13683500.2020.1829568.

[38] L. Huang, "Enhancing the smart tourism experience for people with visual impairments by gamified application approach through needs analysis in Hong Kong”, Sustainability (Switzerland), 12(15), 2020. doi: 10.3390/su12156213.

[39] P. Lee, "Smart tourism city: Developments and transformations', Sustainability (Switzerland), 12(10), 2020. doi: 10.3390/SU12103958.

[40] C. K. Pai, "The role of perceived smart tourism technology experience for tourist satisfaction, happiness and revisit intention", Sustainability (Switzerland), 12(16), 2020. doi: 10.3390/su12166592.

[41] X. Chen, Q. Liu, and X. Qiao, "Approaching Another Tourism Recommender", Proceedings - Companion of the 2020 IEEE 20th International Conference on Software Quality, Reliability, and Security, QRS-C 2020, 2020, pp. 556-562. doi: 10.1109/QRSC51114.2020.00097.

[42] K. V. D. Sagar, P. S. G. Arunasri, S. Sakamuri, J. Kavitha, and D. B. K. Kamesh, "Collaborative Filtering and Regression Techniques based location Travel Recommender System based on social media reviews data due to the COVID-19 Pandemic”, IOP Conference Series: Materials Science and Engineering, 981(2), 2020. doi: 10.1088/1757899X/981/2/022009.

[43] R. Roy, and L. W. Dietz, "TripRec - A recommender system for planning composite city trips based on travel mobility analysis”, CEUR Workshop Proceedings, 2855, 2021, pp. 8-12.

[44] M. Figueredo, "From photos to travel itinerary: A tourism recommender system for smart tourism destination”, Proceedings - IEEE 4th International Conference on Big Data Computing Service and Applications, BigDataService 2018, 2018, pp. 85-92. doi: 10.1109/BigDataService.2018.00021. 